\title{
Climate and Water Cycle in Toilets
}

ISSN: 2637-8078

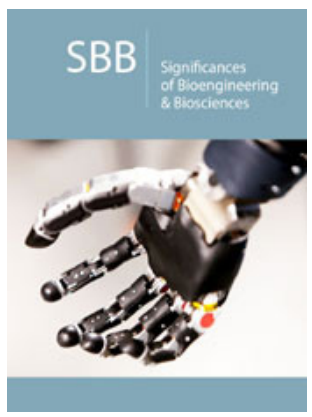

*Corresponding author: Halidullin 0, Ecology Professor, Academician of the Russian Federation LAN, Russia

Submission: 笽 May 31, 2019

Published: 泟June 13, 2019

Volume 3 - Issue 3

How to cite this article: Halidullin 0. Climate and Water Cycle in Toilets.Significances Bioeng Biosci.3(3) SBB.000561.2019

DOI: 10.31031/SBB.2019.03.000561

Copyright@ Halidullin 0, This article is distributed under the terms of the Creative Commons Attribution 4.0 International License, which permits unrestricted use and redistribution provided that the original author and source are credited.

\section{Halidullin 0*}

Ecology Professor, Russia

\section{Opinion}

Humanity exploits water as a liquid working material. The volume of water withdrawn from nature exceeds critical limits. The true cause of climate change is the destruction of the structure of water and its circulation between the atmosphere and the soil. Read more at: If we want to save the lives of our descendants and nature itself, we need a change in our attitude towards water, which will require a change in our entire lifestyle. According to the UN report, 75 percent of river flow is already being withdrawn for various needs. In this case, it is the rivers whose annual resources amount to 47 thousand cubic meters, km, remain the main source of fresh water. All seized water is devoid of natural functions and, after use, evaporates without changing the structure. In fact, water should be used only for drinking. Nature does not provide for boiling, washing, watering, storage in reservoirs. Further exploitation and growth of water resources leads to an increase in natural disasters and catastrophe. One of the many significant types of water destruction is its use in toilet bowls. We dump up to 10 liters with each visit.

For example, it is considered normal, clean drinking water to flush the sewage from the toilet? In case of emergency shutdown of the water supply network, schools, kindergartens, and public institutions are usually closed throughout the city. The main reason for this failure in the flush of toilets. Known devices, when the same water is used many times. In a septic tank, with some sediment, water is stratified by consistency in layers. There is a layer, somewhere closer to the surface, which does not contain solid inclusions. From it, you can take a clear liquid and return it back for flushing, completely disconnecting the flushing tank from the water supply network. The cycle of flush water can be infinite. The water level in the septic tank is continuously replenished from sinks, washing machines, shower. In individual homes it is a septic tank. In apartment buildings, a special floor trap unit is created. During the construction of new houses, the laying of sewage pipes is accompanied by a pipeline and a device that returns the separated liquid back for flushing. This is the process that takes place in the toilets of airliners. There, flushing occurs without a flushing tank, a chemical reagent is added to eliminate odor. This experience should be used in all toilets of all houses, hotels, public buildings. Water for flushing should be used repeatedly. And the feces should not roll through the entire city in order to gather and stand in the vast septic tanks. Own water circulation through the toilet should lead to a sharp decrease in water consumption. Replenishment of such water comes from sinks and soul. One such measure can lead to a decrease in the volume of sewage water. No less expensive water consumption is washing over the sink. Known ways of washing hands over the sinks can also use the experience of using water in the bathrooms of airliners, trains, or tap with motion sensors. It's up to the designers. Purified from chemical elements of detergents, solid inclusions and odor can be used for watering lawns and plants around the house, nearby parks, squares. It must be assumed that all chemical elements of detergents are created for the reliable laundering of dishes, linen, bodies. It may be more rational to change these substances to others, which will not create a smell, will not be able to harm plants and underground living creatures during watering. Implement this principle may be different devices depending on the size of the house, the number of residents, sewage systems. These are design developments and simple re-equipment of bathrooms. The use of such simple means may allow the complete elimination of sewage, and hence the grandiose sewage treatment plants, extensive septic tanks and discharge into rivers. Septic tanks, in addition to pouring large areas, reduce the release of nitrous oxide, which is a greenhouse gas. Ecology is preserved, and artificial evaporation is reduced. Across all cities, such savings can make a significant contribution to the cause of climate change. This can be done through the 
volitional efforts of the leaders of all countries producing sanitary products. Just prohibit the production of obsolete equipment and stimulate the launch and manufacture of devices for a new concept.
A good example of the mass replacement of mass-use devices is the observed transition of all mankind to LED lighting.

For possible submissions Click below: 